\title{
Factors associated with recurrence of postoperative meningioma: a clinical study of 138 patients
}

\author{
Alfotih Gobran, Fang Cheng Li, Xin Ke Xu, Shang Yi Zhang \\ Sun Yat Sen Memorial Hospital, Neurosurgery Department, Sun Yat Sen Medical \\ University, Guang Zhou, Guang Dong Province, People's Republic of China
}

\begin{abstract}
Background and purpose: As the postoperative recurrence of meningioma can have devastating effects, it is important to identify factors that can be used to predict this type of tumor recurrence.

Material and methods: We have performed a retrospective study involving 138 patients who were surgically treated for intracranial meningioma between 2005 and 2010. The patient population consisted of 80 females and 58 males, with an age range of 23 to 77 years old (mean age $=52$ years). We measured associations between meningioma recurrence and clinical features (age, sex, extent of resection, histological type), or radiological features (tumor size, location, shape, calcification, bone changes, brain tumor interface, tumor necrosis, and MRI enhancement).

Results: We found statistically higher levels of postoperative meningioma recurrence in patients with high Simpson grade resections, high histological types, tumor diameters $>5 \mathrm{~cm}$, tumors located in the base of the skull or the parasagittal sinus, tumors with unclear border, irregular enhancements on MRI, edema around the tumor, bleeding and necrosis within the tumor, and irregularly shaped tumors (e.g., lobulated or mushroom-shaped). In addition, calcification, age, sex, bone
\end{abstract}

change, and dural tail sign provided no predictive value.

Conclusions: We have shown that histological type, degree of resection, bleeding, necrosis, edema, irregular enhancement, location, shape, size, and margin serve as strong predictors for the postoperative recurrence of meningioma tumors.

Key words: factors, meningioma, neurosurgery, recurrence.

\section{Introduction}

Meningiomas can remain asymptomatic throughout a person's life and are typically non-life-threatening because they exhibit little (less than $1 \mathrm{~cm}^{2}$ ) or no growth over many years. In a small number of cases, however, these kinds of tumors pose a real danger. This is particularly true during postoperative regrowth of a meningioma, which can cause devastating outcomes for the patient. Our study highlights factors that can be used to predict the recurrence of postoperative meningioma.

\section{Material and methods}

We collected data associated with patients who underwent meningioma resection at the Sun Yat Sen Memorial Hospital between 2005 and 2010. There were 138 patients, of which 58 (42\%) were 
male and 80 (58\%) were female. Ages ranged from 23 to 77 years old, with a mean age of 52.13 years. We excluded patients with multiple intracranial tumors, severe organ failure, patients who underwent postoperative radiation therapy, and patients whose tumor-resection procedure received a Simpson grade of IV or V. The criteria we used to diagnose the recurrence of postoperative meningioma were radiological measurements (e.g., computed tomography (CT) scan, and magnetic resonance imaging $(\mathrm{MRI})$ ) and the recurrence of clinical symptoms after the remission period. To determine the relative risks of meningioma recurrence associated with fifteen independent variables we used the Chi Square Test $(\chi 2)$ to perform binary logistic regression analysis. See Tables 1 and 2.

TABLE 1

Radiological predictors

\begin{tabular}{llcc}
\hline Predictor & & Cases & Percentage (\%) \\
\hline Margin & clear & 128 & 92.8 \\
& unclear & 10 & 7.2 \\
\hline Bone Changes & $(+)$ & 35 & 25.4 \\
& $(-)$ & 103 & 74.6 \\
\hline Calcification & $(+)$ & 25 & 18.1 \\
& $(-)$ & 113 & 81.9 \\
\hline Shape & circular & 113 & 81.9 \\
& lobulated & 17 & 12.3 \\
& mushroom & 8 & 5.8 \\
\hline \multirow{2}{*}{ Dura Tail Sign } & $(+)$ & 61 & 44.2 \\
& $(-)$ & 77 & 55.8 \\
\hline \multirow{2}{*}{ T1 Enhancement } & regular & 119 & 86.2 \\
& irregular & 19 & 13.8 \\
\hline \multirow{2}{*}{ Necrosis } & $(+)$ & 9 & 6.5 \\
& $(-)$ & 129 & 93.5 \\
\hline Bleeding & $(+)$ & 7 & 5.1 \\
& $(-)$ & 131 & 94.9 \\
\hline Edema & $(+)$ & 34 & 31.2 \\
& $(-)$ & 95 & 68.8 \\
\hline Location & parasagittal & 34 & 24.6 \\
& skull base & 47 & 34.1 \\
& other & 57 & 41.3 \\
\hline Size & $\leq 5$ cm & 104 & 75.4 \\
& $>5$ cm & 34 & 24.6 \\
\hline
\end{tabular}


TABLE 2

Clinical predictors

\begin{tabular}{llcc}
\hline Predictor & & Cases & Percentage (\%) \\
\hline Sex & male & 58 & 42.03 \\
& female & 80 & 57.97 \\
\hline Age & $>50$ & 60 & 43.00 \\
& $\leq 50$ & 78 & 57.00 \\
\hline Resection Degree & I & 77 & 47.1 \\
(Simpson) & II & 36 & 31.2 \\
& III & 25 & 21.7 \\
\hline Histological Type & benign & 115 & 87.0 \\
& atypical & 13 & 9.4 \\
& malignant & 10 & 3.6 \\
\hline
\end{tabular}

TABLE 3

Results of comparing radiological factors

\begin{tabular}{|c|c|c|c|c|c|c|}
\hline Predictor & & $\begin{array}{c}\text { Patients } \\
\text { With } \\
\text { Recurrence }\end{array}$ & $\begin{array}{c}\text { Patients } \\
\text { Without } \\
\text { Recurrence }\end{array}$ & $\begin{array}{c}\text { Recurrence } \\
\text { Rate (\%) }\end{array}$ & $\overline{\chi^{2}}$ & $P$ value \\
\hline \multirow[t]{2}{*}{ Margin } & clear & 12 & 116 & 9.4 & \multirow[b]{2}{*}{14.172} & \multirow[b]{2}{*}{0.000} \\
\hline & unclear & 5 & 5 & 50.0 & & \\
\hline \multirow[t]{2}{*}{ Bone Change } & $(+)$ & 9 & 26 & 25.7 & \multirow[b]{2}{*}{7.790} & \multirow[b]{2}{*}{0.05} \\
\hline & $(-)$ & 8 & 95 & 7.8 & & \\
\hline \multirow[t]{2}{*}{ Calcification } & $(+)$ & 3 & 22 & 12.0 & \multirow[b]{2}{*}{0.03} & \multirow[b]{2}{*}{0.957} \\
\hline & $(-)$ & 14 & 99 & 12.4 & & \\
\hline \multirow[t]{3}{*}{ Shape } & circular & 8 & 105 & 7.1 & \multirow{3}{*}{23.500} & \multirow{3}{*}{0.000} \\
\hline & lobulated & 4 & 13 & 23.5 & & \\
\hline & mushroom & 5 & 3 & 62.5 & & \\
\hline \multirow[t]{2}{*}{ Dura Tail Sign } & $(+)$ & 6 & 55 & 9.8 & \multirow[b]{2}{*}{0.624} & \multirow[b]{2}{*}{0.430} \\
\hline & $(-)$ & 11 & 66 & 14.3 & & \\
\hline T1 & regular & 7 & 112 & 5.9 & \multirow[b]{2}{*}{33.151} & \multirow[b]{2}{*}{0.000} \\
\hline Enhancement & irregular & 10 & 9 & 52.6 & & \\
\hline \multirow[t]{2}{*}{ Necrosis } & $(+)$ & 7 & 2 & 77.8 & \multirow[b]{2}{*}{38.149} & \multirow[b]{2}{*}{0.000} \\
\hline & $(-)$ & 10 & 119 & 7.8 & & \\
\hline \multirow[t]{2}{*}{ Bleeding } & $(+)$ & 5 & 2 & 71.4 & \multirow[b]{2}{*}{23.835} & \multirow[b]{2}{*}{0.000} \\
\hline & $(-)$ & 12 & 119 & 9.2 & & \\
\hline
\end{tabular}




\begin{tabular}{lllllll}
\hline Edema & $(+)$ & 13 & 30 & 30.2 & & \\
& $(-)$ & 4 & 91 & 4.2 & 18.557 & 0.000 \\
\hline Location & skull base & 12 & 35 & 25.5 & & \\
& parasagittal & 5 & 29 & 14.7 & & \\
& other & 0 & 57 & 0.0 & & 0.000 \\
& $>5 \mathrm{~cm}$ & 10 & 24 & 29.4 & & \\
\hline Size & $\leq 5 \mathrm{~cm}$ & 7 & 97 & 6.7 & 12.203 & 0.000 \\
& & & & & & \\
\hline
\end{tabular}

TABLE 4

Result of comparing clinical factors

\begin{tabular}{|c|c|c|c|c|c|c|}
\hline Predictor & & $\begin{array}{c}\text { Patients } \\
\text { with } \\
\text { Recurrence }\end{array}$ & $\begin{array}{c}\text { Patients } \\
\text { without } \\
\text { Recurrence }\end{array}$ & $\begin{array}{c}\text { Recurrence } \\
\text { Rate (\%) }\end{array}$ & $\overline{\chi^{2}}$ & $P$ value \\
\hline \multirow[t]{2}{*}{ Sex } & male & 11 & 47 & 19.0 & & \\
\hline & female & 6 & 74 & 7.5 & 4.092 & 0.043 \\
\hline \multirow[t]{2}{*}{ Age } & $>50$ & 5 & 55 & 8.3 & & \\
\hline & $\leq 50$ & 12 & 66 & 15.4 & 1.561 & 0.212 \\
\hline Resection & $\bar{I}$ & 1 & 76 & 1.3 & \multirow{3}{*}{27.023} & \multirow{3}{*}{0.000} \\
\hline \multirow{2}{*}{$\begin{array}{l}\text { Degree } \\
\text { (Simpson) }\end{array}$} & II & 6 & 30 & 16.7 & & \\
\hline & III & 10 & 15 & 40.0 & & \\
\hline \multirow{3}{*}{$\begin{array}{l}\text { Histological } \\
\text { Type }\end{array}$} & benign & 5 & 110 & 4.3 & \multirow{3}{*}{53.271} & \multirow{3}{*}{0.000} \\
\hline & atypical & 4 & 9 & 30.8 & & \\
\hline & malignant & 8 & 2 & 80.8 & & \\
\hline
\end{tabular}

TABLE 5

Binary logistic regression analysis

\begin{tabular}{lcc}
\hline Variable & Influence Score & P value \\
\hline Sex & 4.092 & 0.043 \\
Age & 0.849 & 0.381 \\
Calcification & 0.003 & 0.957 \\
Bone Change & 7.790 & 0.005 \\
Location & 23.500 & 0.000 \\
Irregular Enhancement & 33.151 & 0.000 \\
Edema & 18.557 & 0.000 \\
Dural Tail Sign & 0.624 & 0.430 \\
Shape & 22.228 & 0.000 \\
Margin & 14.172 & 0.000 \\
Necrosis & 38.194 & 0.000 \\
Bleeding & 23.853 & 0.000 \\
Size & 12.203 & 0.000 \\
Resection Degree & 27.023 & 0.000 \\
Histological Type & 52.114 & 0.000 \\
\hline
\end{tabular}


DOI: 10.2478/romneu-2013-0021

\section{Results}

Seventeen patients had a recurrence of meningioma, resulting in a recurrence rate of $12.32 \%$. Ten factors were significant predictors of recurrence, namely the degree of tumor resection, histological type, location, necrosis, bleeding, edema, shape, margin, irregular enhancement, and size $(\mathrm{P}$ $<0.05)$. For the factors sex and bone change, the significance of their predictive value was unclear $(\mathrm{P}=0.043$, and $\mathrm{P}=0.05$, respectively). Histological type, the extent of tumor resection, necrosis, bleeding, location, and irregular enhancement had strong effects on the postoperative recurrence of meningioma. See tables 3, 4, and 5.

To illustrate one case, a 36-year-old male patient presented with a headache that had lasted 6 months and 3 days of vomiting. After being admitted to our department, head MRI revealed a $57 \times 60 \mathrm{~mm}$ compressive cystic solid mass in the right temporal region with surrounding edema. Magnetic resonance spectroscopy results included a reduced $\mathrm{N}$-acetyl aspartate (NAA) peak, an elevated choline (Cho) peak elevated, and a Cho/NAA ratio of 3.18, which suggested a malignant tumor in the right temporal lobe (Figure $1 \mathrm{a}, \mathrm{b}$ ). The patient was subjected to a right temporal lobe lesionectomy. Results of the postoperative tumor biopsy were: anaplastic (malignant) meningioma, WHO grade III (Figure $2 \mathrm{C}, \mathrm{D})$. Three months later the patient started to have a mild headache. A follow up head MRI T2, T1 + C indicated tumor recurrence (Figure $3 \mathrm{~A}, \mathrm{~B}$ ).
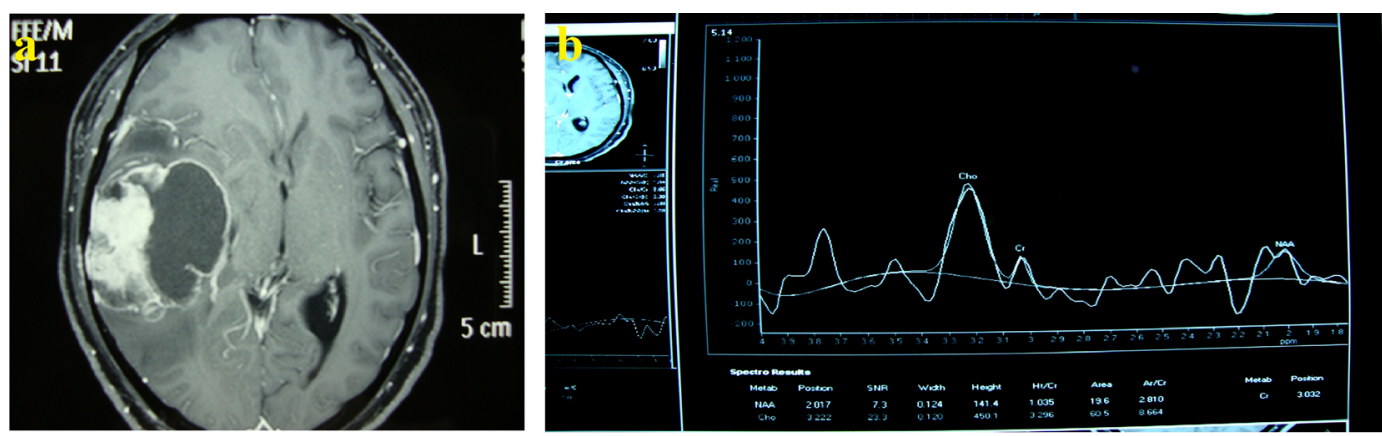

Figure 1 - (a) MRI revealed a $57 \times 60 \mathrm{~mm}$ compressive cystic solid mass in the right temporal region with surrounding edema. (b) Magnetic resonance spectroscopy results included a reduced N-acetyl aspartate (NAA) peak, an elevated choline (Cho) peak, and a Cho/NAA ratio of 3.18, which suggested a malignant tumor in the right temporal lobe
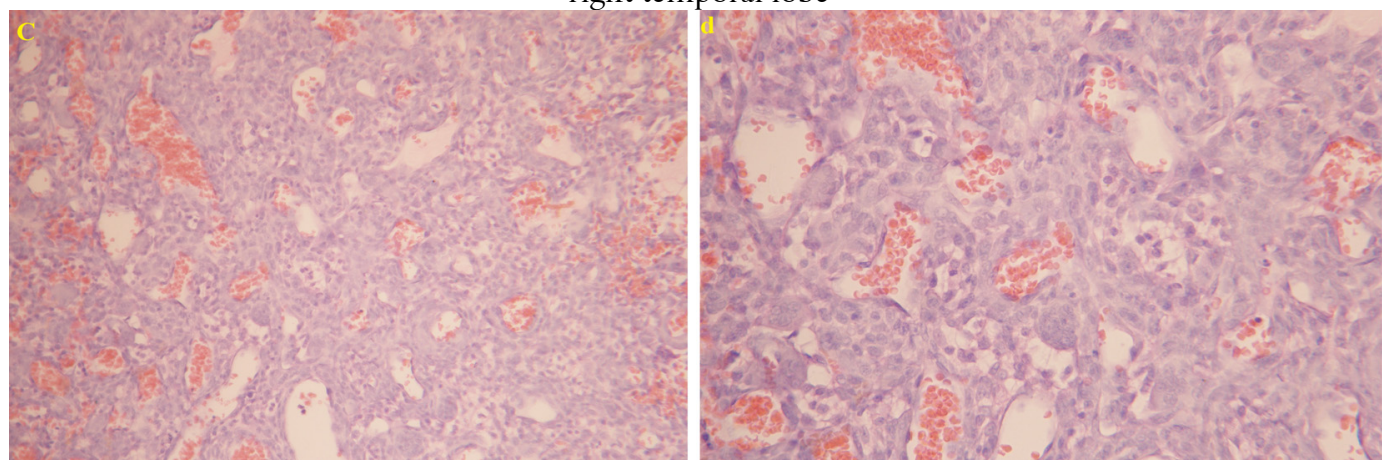

Figure 2

Postoperative tumor biopsy revealed an anaplastic (malignant) meningioma, WHO grade III. loss of meningiomatous tissue and numerous typical and atypical mitoses 

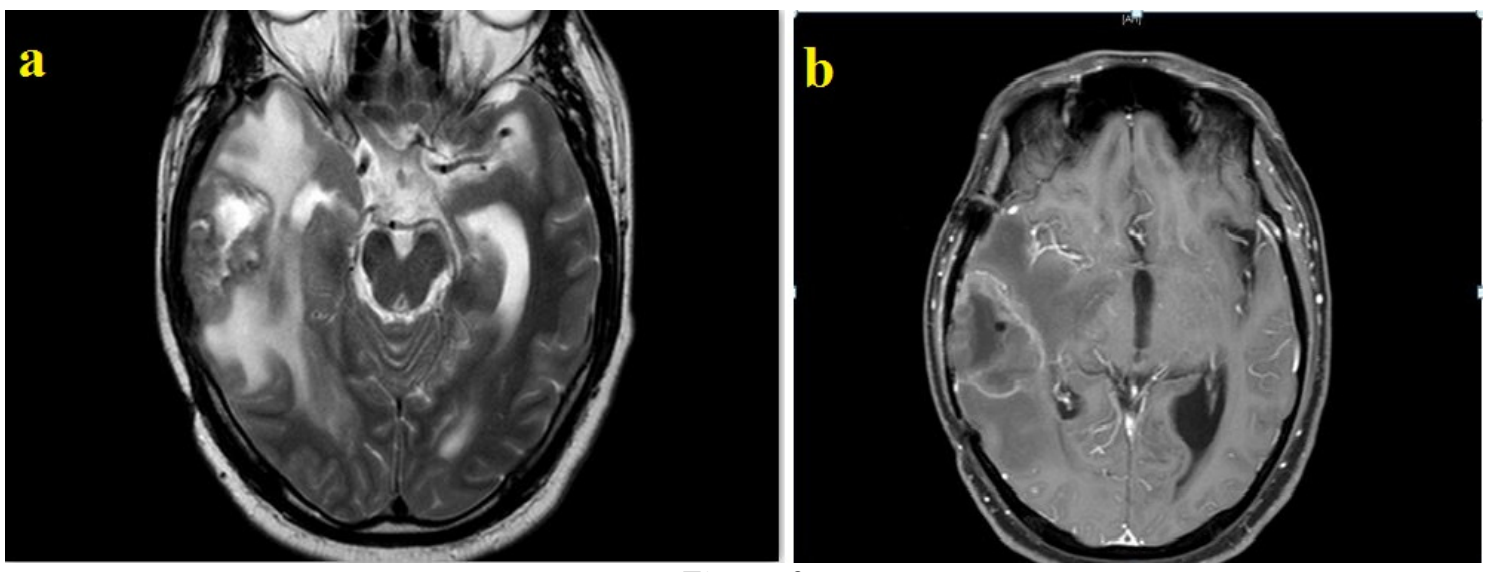

Figure 3

Follow up head MRI T2, T1 + C indicated tumor recurrence

\section{Discussion}

Meningiomas are generally benign tumors that originate from the meninges, in particular cells of the arachnoid villi. These types of tumors represent $\sim 15-20 \%$ of all intracranial tumors, with an annual incidence of $\sim 2$ per 100,000 within the general population. Likelihood of developing meningioma increases with age, as they commonly occur in the fourth to sixth decades of life. Females are twice as likely to be diagnosed with meningioma than males, which may result from the expression of female hormone receptors by meningioma tumors cells [4]. However this sex distribution does not characterize the pediatric population [6].

As mentioned above, meningioma tumors are generally benign, but can recur after surgical resection. Our study shows that meningioma recurrence was significantly associated with a number of predictive factors, namely histological type, the degree of resection, location, edema, necrosis, bleeding, shape, size, enhancement pattern, and margin. Whether patient sex contributes to the recurrence of meningioma remains controversial, as some studies have shown that male patients tend to recur [9], whereas other studies have detected no relationship between sex and recurrence [11]. In our patient sample, the association between sex and recurrence yielded an ambiguous level of significance $(\mathrm{P}=0.043)$. We conclude that sex may not influence the recurrence of meningioma.

Patients in their fourth decade have a higher rate of recurrence than other age groups $[18,20]$. However, our study did not find that age was a significant factor in the recurrence of meningioma $(\mathrm{P}>0.05)$.

Concerning the radiological features of meningioma, we found that location plays the primary role in the recurrence of meningioma. Meningioma can be found in the base of the skull, the parasinuses, the intraventricule system, or on the convexity of the brain far from the sinuses. Meningiomas at the base of the skull and the parasagittal sinus are difficult to treat because these tumors adhere to neurovascular structures. This makes it difficult to perform zero or grade I Simpson resection, providing a chance for these tumors to recur after surgery. We have recommended, therefore, postoperative radiotherapy for residual tumor tissue within these areas [10]. 
The skull bone often reacts to neighboring meningioma, and is sometimes invaded by tumor cells. Meningioma can cause hyperostosis or osteolysis to the nearby skull, and patients with osteolysis show higher recurrence rates than those with hyperostosis [19]. Here we divided our 138 patients into two groups, those with and without bone changes. We found no significant difference between these two groups $(\mathrm{P}=0.05)$

Dural tail sign can be visualized using MRI with contrast agents like gadoliniumdiethylenetriaminepentacetate (Gd-DTPA), and can distinguish between meningiomas that are attached to the dura and other types of tumors. In 1990 Goldsher et al. [5] described dural tail sign as: (1) the presence of at least two consecutive sections through the tumor at the same site in more than one imaging plane, (2) greatest dural thickness adjacent to the tumor and tapering away from it, and (3) more intense enhancement of dural tissue than of the tumor itself. Furthermore, Goldsher et al. suggested that the presence of dural tail sign adjacent to a peripherally located mass is a highly specific sign of meningioma [5]. Tumor cells have been shown to invade the dural tail [15], although this is not always the case [23]. Previous studies have detected no correlations between dural tail sign and meningioma recurrence [13], which agrees with our current result $(\mathrm{P}=0.430)$.

In some rapidly growing forms of meningioma, like anaplastic meningioma, the insufficient supply of oxygen can cause necrosis. Areas of breakdown or bleeding inside a tumor that result from necrosis are characterized by irregular enhancement on MRI T1 Gd-DTPA. These irregular meningioma enhancements, as visualized by CT scans or MRI, have been associated with high rates of recurrence [2, 24]. Others have suggested that hypointense areas or irregular enhancements on CT scans or MRIs indicate malignant types of meningioma [3, 21]. Dietemann et al. found that for 4 of 5 patients with malignant meningioma, their CT/MRI scans revealed irregular enhancement [3]. Patients in our study that had necrosis, bleeding, or irregular MRI enhancements exhibited higher rates of recurrence than others groups $(\mathrm{P}<0.05)$.

We divided patients into three groups based on the shape of the meningioma: spherical, lobulated, and mushroom. There was a significant difference between these three groups $(\mathrm{P}<0.05)$, as spherical, lobulated, and mushroom shapes had recurrence rates of $7.1 \%, 23.5 \%$, and $62.5 \%$, respectively. Previous studies have also shown that mushroom-shaped meningiomas exhibit very malignant behavior $[1,7,16]$.

Most studies have shown that the presence of intratumoral calcification indicates a low rate of tumor recurrence. In fact, levels of calcification and the histological type of the tumor are closely correlated [14]. We have noticed that benign meningioma tumors are generally calcified compared with malignant ones. In addition, calcified meningiomas have low rates of recurrence [14]. Our data show that calcification was not able to predict meningioma recurrence $(\mathrm{P}>0.05)$, but it can be use to differentiate between benign and malignant tumors.

We also divided patients into two groups based on meningioma size: $\leq 5 \mathrm{~cm}$ or $>5$ $\mathrm{cm}$. Although some studies have suggested that large-diameter tumors are more likely to recur [13], we found no significant 
difference between these two groups $(\mathrm{P}$ $0.05)$.

The incidence of edema around meningioma is $\sim 60 \%$ [17]. Peritumoral edema promotes tumor-cell invasion of brain parenchyma, making it more difficult to surgically remove all the tumor cells and increasing the likelihood of recurrence [12]. For patients in our study group the presence of moderate or severe edema resulted in higher rates of recurrence $(\mathrm{P}<$ 0.05).

Clinical care providers are fully aware that meningioma recurrence is related to the extent of resection. As such, the Simpson grading system is used around the world [22]. We have found it difficult to perform grade zero or I resections for tumors: 1) located at the base of the skull, 2) that were invading sinuses, or 3) with unclear margins (particularly tumors with irregular shapes). Our study indicated that higher Simpson grades are associated with higher rates of recurrence.

Finally, we divided meningioma patients into three groups according to world health organization (WHO) histological classifications: benign (I), atypical (II), and malignant (III). Recurrence rates associated with groups I, II, and III were $4.3 \%, 30.8 \%$, $80.0 \%$, respectively, which represented significant differences $(\mathrm{P}<0.05)$. This agrees with a previous report that measured five-years recurrence rates after meningioma resection of $3 \%, 38 \%$, and $78 \%$ for grades I, II, and III, respectively [8].

\section{Conclusions}

We have shown that degree of tumor resection, histological type, pattern of enhancement, necrosis and bleeding within the tumor, peritumoral edema, tumor size, margin characteristics, shape, and location are important factors for predicting the postoperative recurrence of meningioma tumors.

Correspondence address: Alfotih Gobran, Sun Yat Sen Memorial Hospital, Neurosurgery Department, Sun Yat Sen Medical University, P.O. BOX 510120, GuangZhou, GuangDong Province, People's Republic OfChina, Tel: 008613066381670 , email:gta_alfotih@yahoo.com

\section{References}

1. Alvarez F., Roda J.M., Perez R.M, et al. Malignant and atypical meningioma: a reappraisal of clincal, histological and computed tomographic features. Neurosurgery 1987; 20: 688-694.

2. Chen T.C., Zee C.S., Miller C.A., et al. Magnetic resonance imaging and pathological correlates of meningioma. Neurosurgery 1992; 31: 1015-1022.

3. Dietemann J.L., Heldt N., Burquet J.L., et al. CT findings in malignant meningioma. Neuroradiology 1982; 23(4): 207-209.

4. Donnell M.S., Meyer G.A., Donegan W.I. Estrogenreceptor protein in intracranial meningiomas.

Neurosurg 1979; 50: 499-502.

5. Goldsher D., Litt A., Pinto R., et al. Dural "tail" associated with meningiomas on Gd-DTPA enhanced MR images: characteristics, differential diagnostic value, and possible implication for treatment. J Radiology 1999; 176: 447.

6. Haddad G., Al-Mefty O., Abdulrauf S. Meningiomas. In: Winn H.R. [ed.]. Youmans neurologicalsurgery, Vol. 1, Ed. 5. Saunders, Philadelphia 2003, pp. 10991131.

7. Jääskeläinen J., Haltia M., Servo A. Atypical and anaplastic meningioma: radiology, surgery, radiotherapy, and outcome. J Surg Neurol 1989; 3: 101108.

8. Jääskeläinen J. Seemingly complete removal of histologicaly benign intracranial meningioma:late recurrence rate and factors predicting recurrence in 657 patients: a multivariate analysis. J Surg Neurol 1986; 26(5): 461.

9. Kajiwara K., Fudaba H., Tsuha M. et al. Analysis of recurrence of meningiomas following neurosurgical resection. No Shinkei Geka 1989; 12: 1125-1131.

10. Kamitani H., Masuzawa H., Kanazawa I., et al. Recurrence of convexity meningiomas: tumor cells in the arachnoid membrane. J Surg Neurol 2001; 56(4): 228. 
DOI: 10.2478/romneu-2013-0021

11. Mahmood A., Qureshi N.H., Malik G.M. Intracranial meningiomas: analysis of recurrence after surgical treatment. Acta Neuroehir 1994; 126(2-4): 5358.

12. Mantle R.E., Lach B., Deigado M.R., et al. Predicting the probability of meningioma recurrence based on the quantity of peritumoral brain edema on computerized tomography scanning. J Neurosurg 1999; 91(9): 375-383.

13. Nakasu S., Nakasu Y., Nakajima M., et al. Preoperative identification of meningioma that are highly to recur. J Neurosurg 1999; 90: 455-462.

14. Nakasu S., Nakajima M., Matsumura K., et al.Meningioma: proliferating potential and clinicoradiological features. Neurosurgery 1995; 37 : 1049-1055.

15. Nakau H., Miyazawa T., Tamai S., et al. Pathological significance of meningeal enhancement "flair tail" of meningioma on MRI. J Surg Neurol 1997; 48: 584-591.

16. New P.F.J., Hesselink J.R., O’Carroll C.P., et al. Malignant Meningioma: CT and histologic criteria, including a new CT sign. ANJR 1982; 3: 26.

17. Park K.J., Kang S.H., Chae Y.S., et al. Influence of interleukin- 6 on the development of peritumoral brain edema in meningiomas. J Neurosurg 2010;112(1): 73-
80.

18. Perry A., Stafford S.L., Scheithauer B.W., et al. An analysis of histologic parameters. Am J Surg Pathol 1997; 21(12): 1455-1465.

19. Rohringer S., Yoshioka H., Hama S., et al. Recurrence of meningiomas. Cancer 2001; 89(5): 11021104.

20. Stafford S.L., Perry A., Suman V.J., et al. Primarily resected maningioma: outcome and prognostic factors in patients, 1978 through 1988. Mayo Clinic Pro 1998; 73(10): 936-942.

21. Servo A., Porras M., Jääskeläinen J., et al. Computed tomography and angiography do not reliably discriminate malignant tumor from benign one's. Neuroradiol 1990; 32: 94-97.

22. Simpson D. The recurrence of intraeranial meningiomas after surgical treatment. J Neurosurg Psychiatry 1957; 20: 22-39.

23. Tokumaru A., O'uchi T., Eguchi T., et al. Prominent meningeal enhancement adjacent to meningioma on Gd-TPA enhanced MRI images: histopathological correlation. Radiology 1990; 175: 431433.

24. Zee C.S., Chin T., Segall H.D., et al. Magnetic resonance imaging of meningioma. Semin Ulrasound CT MR 1992; 13: 154-169. 